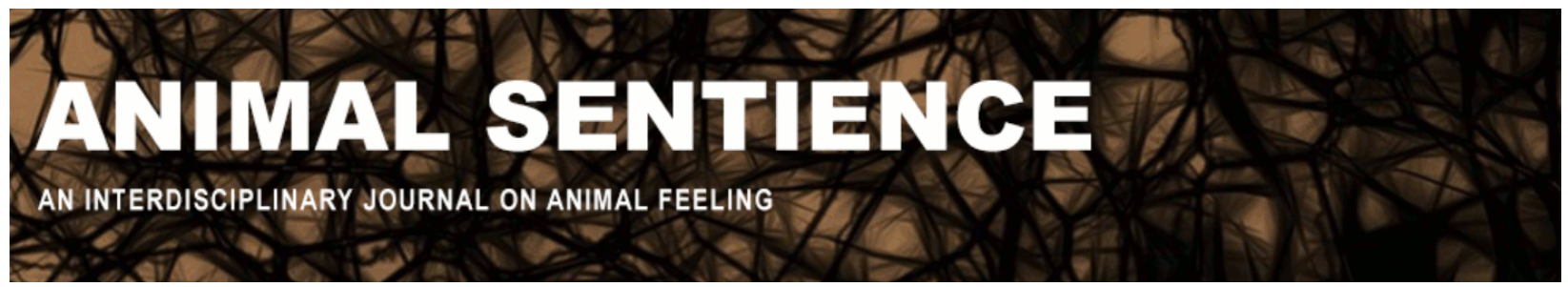

Colombo, Michael and Scarf, Damian (2019) Sheeple? The need for more research on sheep cognition. Animal Sentience 25(12)

DOI: $10.51291 / 2377-7478.1446$

Date of submission: 2019-05-15

Date of acceptance: 2019-05-20

(c)

This article has appeared in the journal Animal

Sentience, a peer-reviewed journal on animal

cognition and feeling. It has been made open access,

free for all, by WellBeing International and deposited

in the WBI Studies Repository. For more information,

please contact

wbisr-info@wellbeingintl.org.

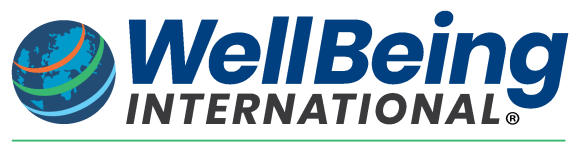

SOLUTIONS FOR PEOPLE, ANIMALS AND ENVIRONMENT 


\title{
Sheeple? The need for more research on sheep cognition
}

Commentary on Marino \& Merskin on Sheep Complexity

\author{
Michael Colombo \& Damian Scarf \\ Department of Psychology \\ University of Otago
}

\begin{abstract}
Marino \& Merskin (2019) provide a comprehensive review of the cognitive abilities of sheep. If research with other animals is any guide, there may be justification for the view that the abilities of sheep have been underestimated, and their review will likely stimulate more research into sheep cognition.
\end{abstract}

\begin{abstract}
Michael Colombo, Professor in the Department of Psychology, University of Otago, conducts comparative cognition research as well as research on the neural basis of learning and memory. Website
\end{abstract}

\begin{abstract}
Damian Scarf, Senior Lecturer, Department of Psychology, University of Otago, conducts comparative and developmental research and is developing a free-range learning apparatus for pigeons (FLAP) to study comparative cognition in free-range animals. Website
\end{abstract}
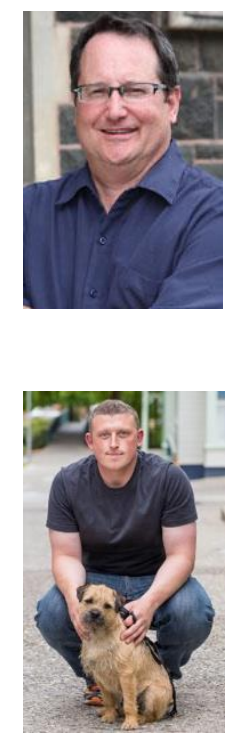

The target article by Marino \& Merskin (2019) is a comprehensive review of the cognitive abilities of sheep, as well as an exploration into aspects of their emotion, personality, and social lives. Through the lens of our own research with pigeons, our commentary will focus on the potential cognitive abilities of sheep.

For a number of years now we have been engaged in a series of studies exploring the cognitive abilities of pigeons, in particular, how they compare to those of primates. In the field of comparative psychology, primates are often viewed as cognitive paragons. Our studies are similar in many ways to the Columba Simulation Project studies conducted in the 70 s and 80 s by B. F. Skinner and Robert Epstein and their colleagues. In these studies, often following the publication of a paper with primates, Skinner, Epstein, and colleagues would train their pigeons to perform a similar task and to a similar level of performance. For example, after Gallup (1970) published a study suggesting that chimpanzees can recognize themselves in a mirror, Epstein, Lanza, and Skinner (1981) published a study showing that pigeons, if properly trained, also display selfrecognition. Similar studies compared pigeons and monkeys on tasks such as symbolic communication (Epstein, Lanza, \& Skinner, 1980) and insight (Epstein, Kirshnit, Lanza, \& Rubin, 
1984). Although these studies were often met with criticism in that the behavior displayed by the pigeons was "shaped" rather than "spontaneous," to many in the field, they called into question the need for cognitive explanations of behavior and seriously challenged the assumption that primates represented some pinnacle of cognition.

In a similar vein, we have set about challenging some of the more recent studies claiming that a certain cognitive ability is unique to primates. For example, for many years a view was held that only primates display a concept of same and different, often referred to in the literature as a "matching concept." We have shown, however, that with proper modifications to the procedures of the tasks, pigeons too can display a matching concept (Colombo, Cottle, \& Frost, 2003). Similarly, for some time, there were thought to be qualitative differences in how primates and pigeons represent sequences. Again, however, with subtle modifications to the original procedure, we were able to show that pigeons not only represent lists (Scarf \& Colombo, 2010) but do so in a similar manner to primates (Scarf \& Colombo, 2011). More recently we have shown that pigeons are on par with primates in numerical competence (Brannon \& Terrace, 1998; Scarf, Hayne, \& Colombo, 2011) and display all the hallmarks of orthographic processing displayed by primates (Grainger, Dufau, Montant, Ziegler, \& Fagot, 2012; Scarf et al., 2016).

The history of research with the humble pigeon demonstrates that, at least with respect to apparent qualitative differences (i.e., differences of kind) between species, the paradigm and procedure hold a great deal of power. Bitterman (1964) raised this issue in the 60s, arguing that differences between the cognitive abilities of species could often be ascribed to contextual variables, that is, non-cognitive factors that impact the performance of an animal on a particular task. As our research and the research of others demonstrates, once these non-cognitive factors are accounted for, the differences between species vanish. One could take this argument one step further and suggest the research supports Macphail's (1985) view that there are no qualitative differences in cognition among vertebrate species. From this perspective, Marino \& Merskin's view probably only scratches the surface of the cognitive abilities of sheep. Indeed, we have conducted a database search using Scopus, focusing on one of the premier journals in comparative psychology (Journal of Comparative Psychology), searching for articles that included a commonly utilized species (i.e., monkey, chimpanzee, pigeon, and sheep) in the title, abstract, or keywords. As Figure 1 shows, comparative research with sheep is a relative rarity, highlighting the potential of research in this area to uncover abilities in sheep that are comparable to those of primates and pigeons.

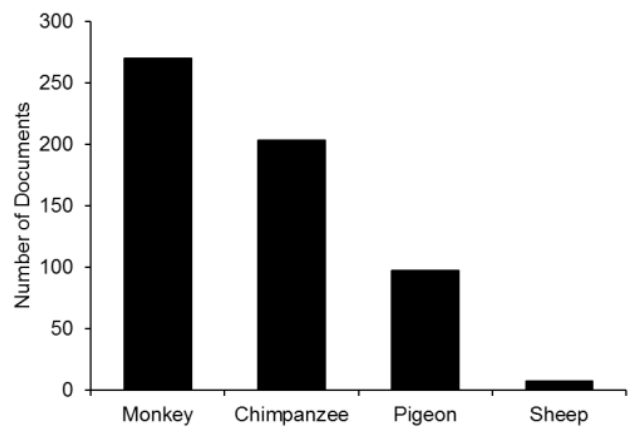

Figure 1. Number of documents identified in Scopus. The search was limited to the Journal of Comparative Psychology, and the article had to mention the particular species in the title, abstract, or keywords. 
One might argue that we are at risk of encouraging an overly rich or optimistic view of the future of cognitive research with sheep. Typically, we are firmly in the killjoy camp when it comes to these matters (Scarf, Imuta, Colombo, \& Hayne, 2012). However, at the risk of being classified as sheeple (i.e., docile, foolish, or easily led), we think Marino \& Merskin make a sound case that sheep cognition has a great deal of potential. Moreover, Zentall (2001) has noted that speculations about the cognitive processes underlying animal behavior, whether or not they turn out to hold true, stimulate a great deal of research. Thus, with the risk of being easily led in mind, we hope Marino \& Merskin's target article stimulates more research on sheep cognition.

\section{References}

Bitterman, M. E. (1964). The evolution of intelligence. Scientific American, 212, 92-100.

Brannon, E. M., \& Terrace, H. S. (1998). Ordering of the numerosities 1 to 9 by monkeys. Science, 282(5389), 746-749.

Colombo, M., Cottle, A., \& Frost, N. (2003). Degree of representation of the matching concept in pigeons (Columba livia). Journal of Comparative Psychology, 117(3), 246-256.

Epstein, R., Kirshnit, C. E., Lanza, R. P., \& Rubin, L. C. (1984). 'Insight' in the pigeon: antecedents and determinants of an intelligent performance. Nature, 308(5954), 61-62.

Epstein, R., Lanza, R. P., \& Skinner, B. (1981). "Self-awareness" in the pigeon. Science, 212, 695696.

Epstein, R., Lanza, R. P., \& Skinner, B. F. (1980). Symbolic communication between two pigeons (Columba livia domestica). Science, 207(4430), 543-545.

Gallup, G. G. (1970). Chimpanzees: self-recognition. Science, 167(3914), 86-87.

Grainger, J., Dufau, S., Montant, M., Ziegler, J. C., \& Fagot, J. (2012). Orthographic processing in baboons (Papio papio). Science, 336(6078), 245-248.

Macphail, E. (1985). Vertebrate intelligence: the null hypothesis. Philosophical Transactions of the Royal Society of London, Series B: Biological Sciences, 308(1135), 37-51.

Marino, L. \& Merskin, D. (2019) Intelligence, complexity, and individuality in sheep. Animal Sentience 25(1).

Scarf, D., \& Colombo, M. (2010). Representation of serial order in pigeons (Columba livia). Journal of Experimental Psychology: Animal Behavior Processes, 36(4), 423-429.

Scarf, D., \& Colombo, M. (2011). Knowledge of the ordinal position of list items in pigeons. Journal of Experimental Psychology: Animal Behavior Processes, 37(4), 483-487.

Scarf, D., Boy, K., Reinert, A. U., Devine, J., Güntürkün, O., \& Colombo, M. (2016). Orthographic processing in pigeons (Columba livia). Proceedings of the National Academy of Sciences, 113(40), 11272-11276.

Scarf, D., Hayne, H., \& Colombo, M. (2011). Pigeons on par with primates in numerical competence. Science, 334(6063), 1664.

Scarf, D., Imuta, K., Colombo, M., \& Hayne, H. (2012). Social evaluation or simple association? Simple associations may explain moral reasoning in infants. PloS ONE, 7(8), e42698.

Zentall, T. R. (2001). The case for a cognitive approach to animal learning and behavior. Behavioural Processes, 54(1-3), 65-78. 